\title{
HYPERTROPHIC OSTEO-ARTHROPATHY IN POLYARTERITIS
}

BY

\author{
R. R. H. LOVELL AND G. B. D. SCOTT \\ From the Medical Unit and Department of Morbid Anatomy, St. Mary's Hospital, Paddington
}

(RECEIVED FOR PUBLICATION AUGUST 16, 1955)

Hypertrophic osteo-arthropathy is most commonly associated with bronchopulmonary or pleural diseases. It has also been described in several apparently unrelated conditions and occasionally in patients with no other recognizable disease. The literature is reviewed by Mendlowitz (1942). This paper reports hypertrophic osteo-arthropathy in a patient with polyarteritis nodosa and describes the effect of cortisone.

\section{Case Report}

A male business executive, aged 51, had suffered no serious illness until 1947, when he started to get aching pains in the backs of the thighs; the pains were constant, and worse when he was tired, but unaffected by movement. Early in 1948 his right ankle became swollen and he developed painful red papules, up to $3 \mathrm{~mm}$. diameter, some of which ulcerated. About this time purple mottling was noticed on the legs and forearms. Later in 1948 his knees became swollen and painful but he was able to play golf. Early in 1949 the wrists, elbows, and metacarpo-phalangeal joints were painful and swollen and he suffered increasingly severe limb pains unrelated to joints. During 1950 he was disabled by pain, for which he took up to 24 tablets codeine co. B.P. daily. He now noticed small nodules under the skin; he sweated profusely and lost about $7 \mathrm{lb}$. weight in 6 months. Apart from symptoms of a sudden right subclavian venous thrombosis while playing golf in 1949, his symptoms from 1947 to 1950 related only to the skin and locomotor system. He was seen in 1950 by Dr. W. S. C. Copeman and Dr. G. B. Mitchell-Heggs and was admitted to St. Mary's Hospital with a suggested diagnosis of polyarteritis nodosa.

Clinical Examination.-On admission in November, 1950, his limbs were very painful. There was swelling round the elbows, wrists, metacarpo-phalangeal, knee, and ankle joints. The swelling was due partly to synovial effusions, but there was also conspicuous peri-articular thickening extending 2-3 inches beyond the joints. The wrists, knees, and ankles were warm, but movements were free. There was slight clubbing of the fingers.

The skin showed three types of lesion typical of polyarteritis:

(a) purple mottling, most marked on the distal parts of the arms and legs;

(b) tender punched-out ulcers over the buttocks and scars of similar lesions which had healed; (c) subcutaneous nodules about $3 \mathrm{~mm}$. diameter on the forearms.

Apart from dilated superficial collateral veins consistent with an occlusion of the right subclavian vein, the other systems appeared healthy. The blood pressure was $105 / 65 \mathrm{~mm}$. $\mathrm{Hg}$.

\section{Laboratory Investigations}

Blood: Erythrocyte sedimentation rate (Westergren) $75 \mathrm{~mm} . / 1 \mathrm{hr}$.

Haemoglobin $11 \cdot 1$ g. $/ 100 \mathrm{ml}$., 3,800,000 red cells/ c. mm., 15,000 white cells/c. mm. with 75 per cent. neutrophils, 19 per cent. lymphocytes, 3 per cent. eosinophils and 3 per cent. monocytes.

Urine: No abnormality.

Radiology: Appearance of heart and lungs normal. Hands, wrists, and elbows showed no joint changes. Knees showed some osteophytic lipping. Lower ends of shafts of forearm bones showed minimal irregular formation of new sub-periosteal bone (Fig. 2a, opposite).

Biopsy: Diagnosis of polyarteritis confirmed by finding of typical necrotizing arteritis in sections of a subcutaneous nodule (Fig. 1, opposite).

Clinical Course.-Treatment was started with corticotrophin $100 \mathrm{mg}$. daily by intramuscular injection. Within 4 days all limb and joint pains had gone, by the $\rightleftharpoons$ second week there was no joint swelling, and by the third week the skin ulcers had healed. The erythrocyte sedimentation rate fell to normal by the fourth week. The dose of corticotrophin was reduced to $50 \mathrm{mg}$. daily in the fifth week, following which there was a recurrence 3 . of limb pains and fresh skin lesions appeared; the biopsy of one of these again showed active polyarteritis.

During the next 3 years the patient was maintained on an average dose of $100 \mathrm{mg}$. cortisone daily. Despite $\frac{\text { S }}{3}$ some limb pain and joint swelling he lost no time from $D$ work and was able to play golf twice a week. After 3 years, however, ulcers developed around the ankles and $\bar{N}$ on the legs; patches of skin on his feet became cold and $O$ blue, and the arterial pulses in the feet diminished. The $N$ ulcers enlarged and deepened, exposing muscles and ten- $N$ dons over areas up to $16 \mathrm{~cm}$. across. Their expansion $\omega$ appeared unaffected by increasing the dose of cortisone to $400 \mathrm{mg}$./day, though on this dose all synovial effusions 6 and periarticular swellings disappeared, and limb pains, $\mathbb{\Phi}$ other than those arising in the ulcers, disappeared.? However, the pain in the extending ulcers became in- 7 tolerable and the left leg was amputated above the knee in July, 1954, by Professor C. G. Rob, and 9 days later the patient died with a pulmonary embolus. 


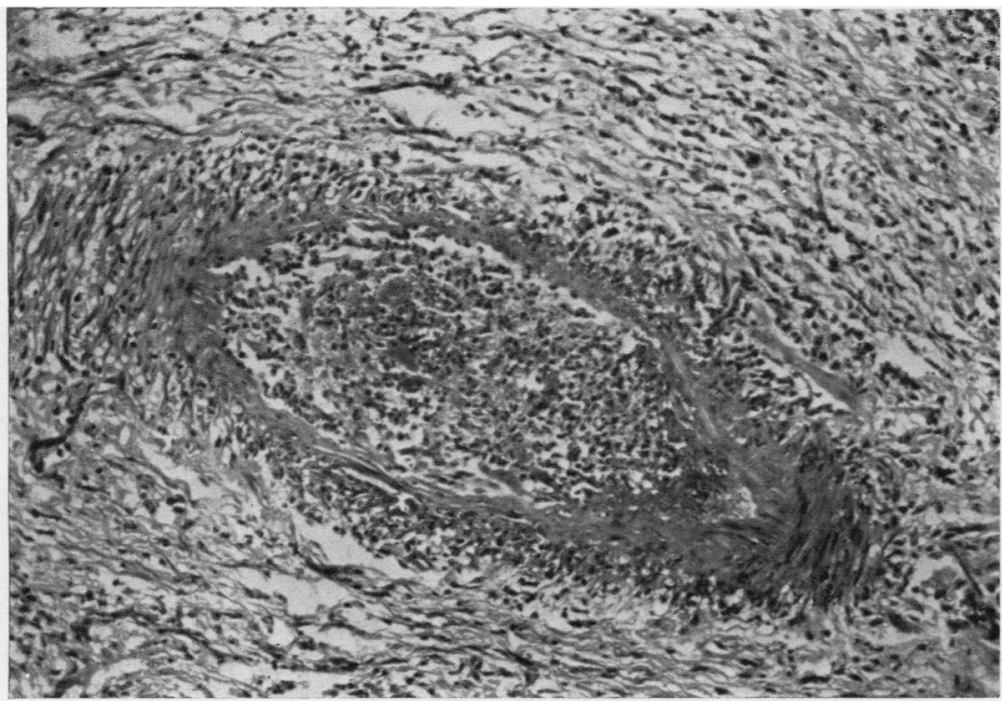

Fig. 1.-Artery showing inflammation and necrosis in a section through a subcutaneous nodule removed in December, 1950.
Up to the time of death there had been no clinical or radiological evidence of disease in the heart or lungs. During $3 \frac{1}{2}$ years of cortisone treatment the blood pressure rose steadily from $105 / 65 \mathrm{~mm}$. $\mathrm{Hg}$ to $165 / 105 \mathrm{~mm}$. $\mathrm{Hg}$, though the only evidence of renal abnormality in this period was the finding twice of a few red cells and once of a few granular casts in fifteen examinations of urine deposit. Symptoms and signs relating to the joints had been suppressed for 3 months before death.

Radiological Changes in Joints and Bones.-The joints of the hands, wrists, knees, and ankles were examined radiologically at intervals from 1950 to 1954 ; there were no changes in them other than those associated with synovial effusions.

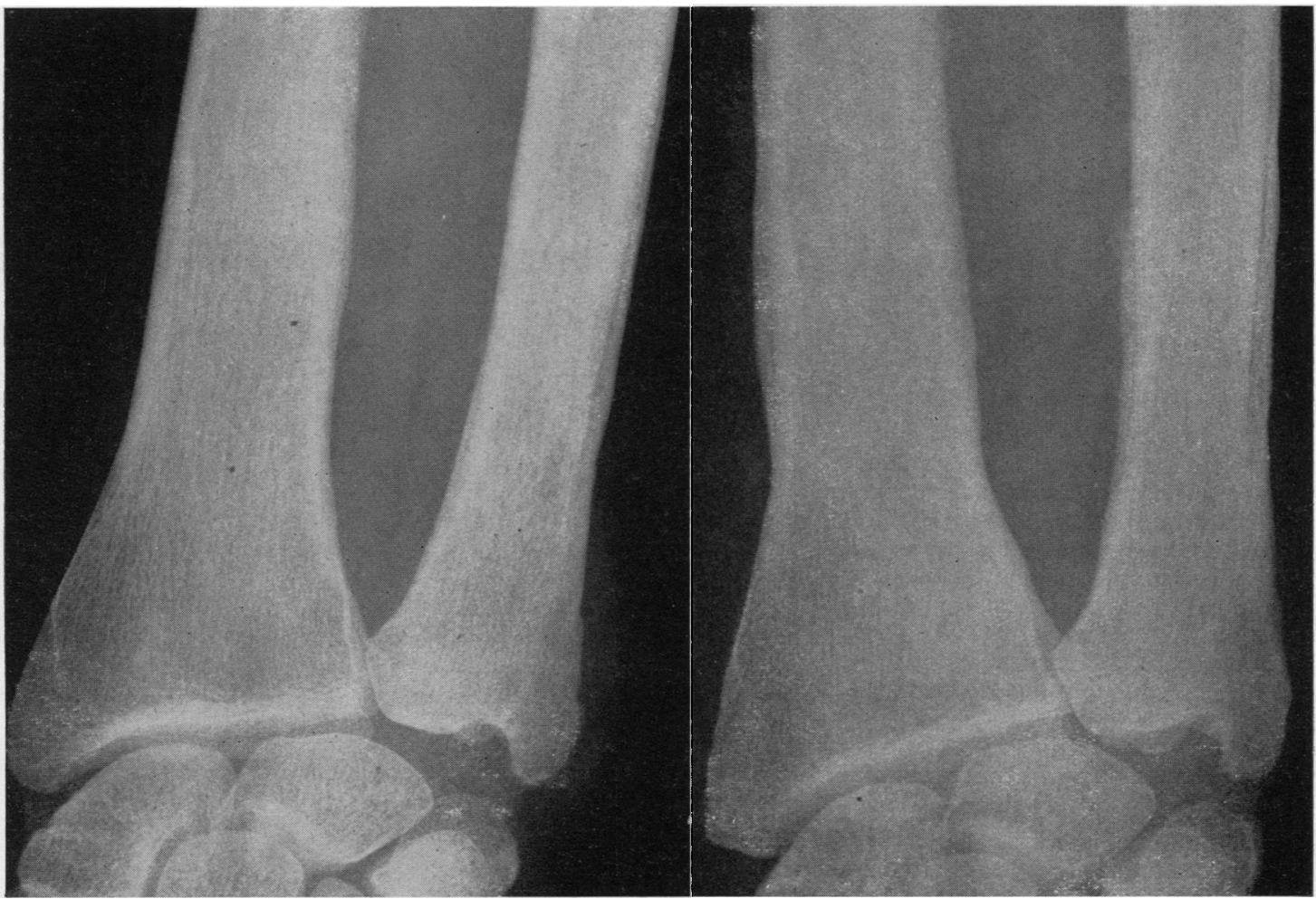

Fig. 2(a).-Right radius and ulna, showing minimal periosteal proliferation in 1950 .
Fig. 2(b).-Right radius and ulna, showing more advanced periosteal changes in 1953. 



Fig. 4. - Thickened periosteum over a nodule excised at necropsy $(\times 180)$.

Fig. 3.-Right tibia and fibula, showing periosteal changes in 1953 .

The first extensive examination of the long bones was made in 1952 , when changes were disclosed similar to those found in the forearms in 1950; subperiosteal new bone was now more conspicuous in the forearm bones and was present also in the tibiae and fibulae. A comparison of the appearances of the right radius and ulna in 1950 and

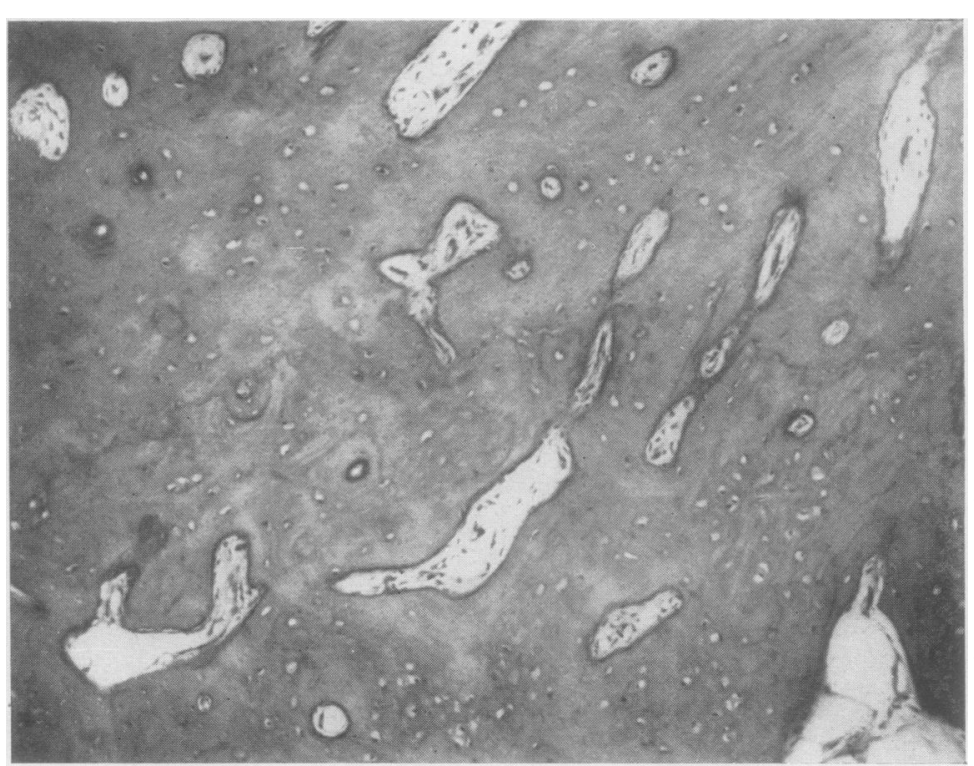

Fig. 5.-Irregular subperiosteal bone in same nodule as Fig. $4(\times 100)$. 1953 shows that changes progressed during this period (Fig. 2). The appearances of the right tibia and fibula in 1953 are shown in Fig. 3.

Necropsy Findings.-An embolus occluded both main branches of the pulmonary artery. No active polyarteritis was found; two healed arterial lesions had been found in the skin of the amputated leg. The ulcers on the legs showed non-specific inflammation and were surrounded by dense fibrous tissue. The liver was pale

and fatty, a change commonly seen in Cushing's syndrome and in patients receiving large doses of cortisone. The other viscera were normal.

Pathology of Joints and Bones.-Dissection of the knees and ankles showed much peri-articular fat. Otherwise $\bar{O}$ their macroscopic appearances were normal. On $\overrightarrow{\mathbb{D}}$ microscopy the synovial membranes and articular surfaces were normal. 
A nodular area was excised from the anterior surface of the lower part of the left tibia. The periosteum showed a clear division into two layers but there was no inflammatory reaction (Fig. 4). Beneath the periosteum there was a layer of newly-formed bone, showing no regular structure (Fig. 5). The appearance was in striking contrast to the lamellated compact bone of the underlying cortex (Fig. 6).

\section{Discussion}

Symptoms relating to the joints are common in polyarteritis and conform usually to one of two types (Lovell and Rose, 1955). There is either an acute, transient, sometimes migratory, arthritis, or a more chronic deforming arthritis resembling rheumatoid disease. Both types of arthritis are suppressed by cortisone. There is no doubt that this patient had polyarteritis, for the skin biopsies were unequivocal as were the appearances of the skin lesions. While the joint lesions might have been due to polyarteritis, their clinical features were typical of hypertrophic osteo-arthropathy. The associated finger clubbing and radiological and pathological changes in the bones show that hyper- trophic osteo-arthropathy was indeed present.

The histological appearances in the joints and bones differed from those described in hypertrophic osteo-arthropathy by Gall, Bennett, and Bauer (1951) in only one respect, namely the absence of inflammatory changes in the joint tissues and in the periosteum. We confirmed the observation of these authors that inflammatory changes with lymphocytic infiltration are normally features of osteoarthropathy by examining the tibial periosteum from a male aged 48 who died with this disease associated with a bronchial carcinoma. Fig. 7 shows a typical portion of periosteum from the tibia of this patient; the lymphocytic reaction contrasts strongly with the appearance in our patient (Fig. 4). Since, in our patient, cortisone had suppressed the clinical manifestations of joint inflammation and the limb pains for 3 months before he died, it seems likely that the absence of the inflammatory component of osteo-arthropathy on histological examination may be attributed to the effect of cortisone. With the doses of cortisone used, the irregular deposition of new cortical bone progressed.

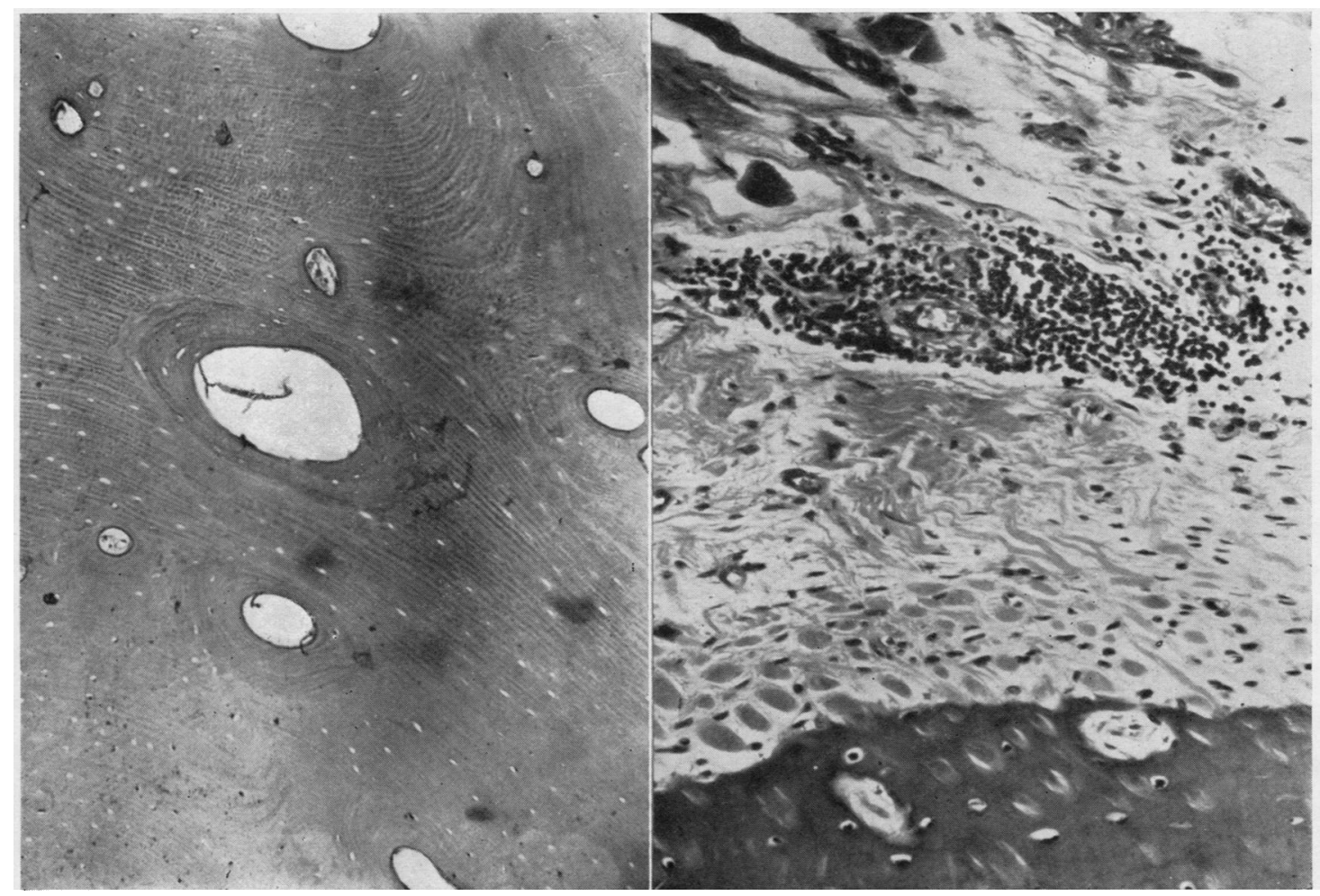

Fig. 6.-Normal lamellated bone underlying periosteal nodule $(\times 100)$.
Fig. 7.-Lymphocytic reaction in periosteum of a patient with hypertrophic osteo-arthropathy who did not receive cortisone $(\times 180)$. 


\section{Summary}

The occurrence of hypertrophic osteo-arthropathy is described in association with polyarteritis. Cortisone suppressed the arthritis and probably suppressed the inflammatory component of the periosteal reaction.

We thank Prof. G. W. Pickering and Dr. G. B. Mitchell-Heggs for permission to report this case.

\section{REFERENCES}

Gall, E. A., Bennett, G. A., and Bauer, W. (1951). Amer. J. Path., 27, 349.

Lovell, R. R. H., and Rose, G. A. (1955). Postgrad. med. J., 31, 382. Mendlowitz, M. (1942). Medicine (Baltimore), 21, 269.
Ostéoarthropathie hypertrophique dans la polyartérite

RÉSUMÉ

On décrit l'incidence de l'ostéoarthropathie hypertrophique en association avec la polyartérite. La cortisone supprima l'arthrite et, probablement, le composant inflammatoire de la réaction périostique.

\section{Osteoartropatia hipertrófica de la poliarteritis}

SUMARIo

Se describe la ocurrencia de la osteoartropatia hipertrófica en asociación con la poliarteritis. La cortisona suprimió la artritis y, probablemente, el componente inflamatorio de la reacción perióstica. 